\title{
Managing e-waste from a closed-loop lifecycle perspective: China's challenges and fund policy redesign
}

\author{
Tingting Tian ${ }^{1,2,3} \cdot$ Guangfu Liu ${ }^{2} \cdot$ Hussein Yasemi ${ }^{3} \cdot$ Yang Liu $^{3}(0)$
}

Received: 26 August 2021 / Accepted: 10 February 2022 / Published online: 19 February 2022

(c) The Author(s) 2022

\begin{abstract}
E-waste is one of the fastest growing streams of solid waste globally, and its effective management has become a focused issue, which requires a deep understanding of the core guiding theory of extended producer responsibility (EPR). Over the past 20 years, China, one of the world's largest producers of electrical and electronic equipment (EEE), has made great efforts to improve e-waste management along with the massive generation of e-waste. In 2012, China implemented a unique EPR-based e-waste fund policy. However, the fund policy is unsustainable due to the challenges of non-closed resource use, informal recycling, and fund imbalance. Beginning with an overview of these challenges, this paper focuses on redesigning the fund policy from a closed-loop lifecycle perspective in order to maintain a balanced development of the resource use loop and the fund system in China's ten-year plan. In doing so, two EPR instruments, recycling content standards and consumer-oriented deposits, are added to the current fund policy. Subsequently, three extension scenarios alternately changed a critical parameter of the model to test the impact on sustainable capabilities. In this way, the sustainable supply of funds and secondary resources for the e-waste industry can be established in China and effectively demonstrate solid waste management in developing countries.
\end{abstract}

Keywords E-waste management $\cdot$ Fund policy redesign $\cdot$ Extended producer responsibility $\cdot$ Sustainability $\cdot$ China

\section{Introduction}

Over the last few decades, the consumption of electrical and electronic equipment (EEE) has greatly increased with the advancement of technology and the improvement of people's living standards (Shittu et al. 2021). High consumption is always accompanied by a high yield of waste due to service lifetime limitations (Gu et al. 2016). Approximately 54 million tons of e-waste were generated globally in 2019, and it is speculated that this figure will ascend to 74.7 million tons by 2030 , with an average annual growth rate of 3-5\% (Arya

Responsible Editor: Baojing Gu

Yang Liu

yang.liu@liu.se

1 Business Division, Institute of Textiles and Clothing, The Hong Kong Polytechnic University, Hong Kong, China

2 School of Economics and Management, Tongji University, Shanghai 200092, China

3 Department of Management and Engineering, Linköping University, SE-581 83 Linköping, Sweden and Kumar 2020; Ilankoon et al. 2018). E-waste is an attractive "urban mineral" because it contains various valuable resources such as gold, silver, copper, and other precious metal elements (Ogunniyi et al. 2009; Yang et al. 2020). It is an environmental contaminant simultaneously because of its embedded heavy metals, flame retardants, and refrigerants that can pose a severe threat to the environment and human health without proper treatment (Sovacool 2019). Thus, the recovery of these secondary resources from e-waste has significant benefits for resource conservation and pollution prevention (Wang et al. 2019). However, most e-waste is usually "backyard recycled" through illegal and backward informal channels, landfilled, incinerated, or directly dumped (Chi et al. 2011). Only a small amount, less than $20 \%$, of global e-waste is recycled by formal take-back systems (Patil and Ramakrishna 2020).

Under the pressure to minimise the environmental impact of e-waste disposal, many legislative documents have been activated under the guidance of extended producer responsibility (EPR). EPR shifts the physical and/or financial responsibility for e-waste from the municipalities to the original producers, thus providing effective financial and/or physical 
links between producers and recyclers (Kaffine and O'Reilly 2013). To some extent, EPR is better viewed as a framework within a bound of policies based on three basic categories of instruments: take-back requirements, economic instruments, and performance standards (Kaffine and O'Reilly 2013). Policymakers can select from EPRs that can be flexibly adapted to national and regional values, legislative particularities, or economic contexts. EPR is regarded as a core guiding theory to sustain the development of a recyclingoriented circular economy and has been adopted in many EU countries, the USA, Japan, and China (Gu et al. 2017; Xu et al. 2021). The WEEE Directive (Directive 2012/19/EU) and the RoHS Directive (Directive 2011/65/EU) are the most relevant examples, which emphasise take-back requirements that $65 \%$ of electronic equipment sold or $85 \%$ of e-waste generated must be recycled (Berežni et al. 2021).

China is one of the largest manufacturers and consumers of EEE globally and undoubtedly generates a large amount of e-waste (Liu et al. 2017). According to previous global trends, the USA generated the highest e-waste. However, the latest statistical report shows that China generated more e-waste with 11.17 million tons, followed by the USA with 7.63 million tons, India with 3.56 million tons, Japan with 2.83 million tons, and Brazil with 2.36 million tons in 2019 (Statista 2021). Meanwhile, China's e-waste generation is predicted to grow to 27.2 million tons by 2030 (Zeng et al. 2020). This situation may be exacerbated if effective measures do not curb it ( $\mathrm{Li}$ and Achal 2020). To promote e-waste management, in 2012, China issued certificates to 109 formal recyclers and proposed a unique EPR program known as the fund policy (State Taxation Administration of People's Republic of China 2012). The fund policy assigns financial responsibility to producers for products' entire life, especially post-consumption, intending to subsidise certified recyclers to increase recycling (Cai et al. 2020). Currently, five categories of electronics, as shown in Fig. 1, including televisions (TV), refrigerators (RE), washing machines (WM), air conditioners (AC), and computers (PC), are on the fund management list with different levies and subsidies standards (Fu et al. 2020). There is no doubt that the fund policy-based e-waste management system plays a key role in the entire life cycle of e-waste in China, but it also faces some challenges that may cause it to stagnate (de Albuquerque et al. 2020).

This paper focuses on the fund policy redesign that provides specific operational strategies for critical links of the entire life cycle based on clarified challenges to manage e-waste dynamically. Accordingly, the contribution of this study to the existing literature is threefold. First, to the best of our knowledge, this is the first study to redesign the e-waste fund policy from a closed-loop lifecycle perspective. Most existing literature investigates the market responses and environmental performance of introducing the fund policy. However, limited literature discussed the availability of sustainable funds and secondary resources throughout the life cycle, which is the focus of this study. Second, our proposed framework provides a new angle for e-waste management by involving two EPR instruments, consumer deposits and recycling content standards, to operationalise closed-loop in both resource and fund flows. Finally, this study creatively compares the feasibility of the redesigned policy under "what if" scenarios of adjusting recycling content standards, recycling rate, and loss rate of precious resources and puts forward corresponding schemes. As such, the redesigned model can flexibly adapt to some changes based on technical levels or regional characteristics and thus is expected to guide policymakers to make better-informed decisions.

The remainder of this study is organised as follows. "A review of China's e-waste management challenges" provides a literature review of China's e-waste management challenges under the fund policy. In "The fund policy redesign based on the closed-loop life cycle", a redesigned framework that integrates two EPR tools (recycling content standards and consumer-oriented deposits) into the current fund policy is proposed. "Results analysis" discusses the case study results to demonstrate the feasibility of the redesign scheme, followed by a sensitivity analysis to test the impact of some critical variables (e.g. recycling resources content, recycling rates, and resource extraction rate). We present management insights and overall concluding remarks in "Discussion" and "Conclusions".

\section{A review of China's e-waste management challenges}

Originally, recycling funds intended to internalise the externalities of e-waste treatment in the form of producer/consumer payments (Puig-Ventosa 2004). In current practice, many countries have adopted different fund schemes to support e-waste recycling activities, such as Switzerland, Norway, the Netherlands, Sweden, and Australia. In California, funds levied from consumers are used for recycling infrastructure building, while in Switzerland and Norway, these funds are used to subsidise the recycling costs for recyclers (Nixon and Saphores 2007; Streicher-Porte 2006). Somewhat different in the way it is funded, China's fund policy collects funds from producers rather than consumers and then subsidises recyclers according to the amount of e-waste recycled (Hischier et al. 2005; Uwasu et al. 2013). Due to the uniqueness of the fund policy, research interest in China's e-waste management has increased significantly and developed in the past decade (Li et al. 2015; Liu et al. 2021; Zeng et al. 2017). Existing literature discusses the issue of 
introducing the fund policy-centred management system and investigating the market responses to it (Cao et al. 2016; Yang et al. 2020). In detail, the debate often focuses on how the regulatory regime influences market behaviour or environmental goals, as well as the technical development and economic performance of the e-waste industry (Guo et al. 2018; Liu et al. 2020; Tang and Wang 2014; Wang et al. 2018; Zhang et al. 2015). Arguably, a common view is pointed out in these studies that the current fund policy has not yet met expectations in terms of environmental and economic performance and even faces a series of challenges.

Herein, three main challenges are elucidated from the related publications.

(1) Difficulty in closing the resource loop. The fund policy encourages producers to use secondary resources, facilitating source reduction and waste utilisation (Mayyas et al. 2012). Special emphasis is placed on producers paying less if they design new products considering their environmental and natural resource impacts $(\mathrm{Gu}$ et al. 2017). However, there are no relevant detailed regulations to enforce it, so it is difficult to incentivise producers to use secondary inputs from e-waste.

(2) Competition with informal channels. Informal initiatives exist in most developing countries, especially in China. It is very profitable due to the high demand for secondary resources and the low wages of unskilled workers (Yang et al. 2008). In 2019, only $20 \%$ of e-waste was recycled by formal recyclers, whereas the majority was recycled by informal recyclers (Tang and Wang 2014). In Cao et al. (2016)'s study, this proportion has reached 50\% in China's Zhejiang province. The positive contribution of the informal system to waste recycling is acknowledged. However, the environmental problems it causes cannot be ignored, and this issue has been well documented in academia (Botello-Álvarez et al. 2018). It responds only to market demand for high-value waste while leaving others to landfill (Ezeah et al. 2013). This poses a challenge to the stability of e-waste management. Incentives for consumers to give back e-waste to designated collection points are necessary for the long run yet are hard to realise now (Xue et al. 2019). The main reason for this phenomenon is that informal recyclers prefer to pay higher prices than formal recyclers. Take computer waste as an example. In addition to being provided doorto-door service, consumers get 100-150 RMB more if they choose informal channels, which is a great attraction to consumers (Gu et al. 2017).

(3) The dilemma of funds supply. The fact that the funds levied from producers are much lower than the subsidies to recyclers leads to a serious dilemma for the fund system: it cannot pay for itself (Gu et al. 2017; Zeng et al. 2017). This paper estimates that the gap between the funds and subsidies was RMB 0.6 billion in 2013 covered by the government. This deficit is likely to increase further as e-waste generation grows and is estimated to grow to RMB 23.15 billion by 2030 (assuming a recycling rate of 0.55 ). This imbalance betweenfunds and subsidies may lead to a huge burden on the government and impede the sustainable development of e-waste management in China (Liu et al. 2020).

How to address such challenges and further promote the operation of the fund policy-based e-waste management system is an urgent issue. In the study by Gu et al. (2017), a new fund operation mode was established with the addition of consumer payments, and the authors also extended the new model to address the incentive problem of eco-design. Similarly, Hong et al. (2014) described a conceptual fund balance model to determine the socially optimal standards of the funds and subsidies in a closed-loop supply chain. Nevertheless, we should note that the optimal decisions in these studies focus only on piecemeal links and ignore the impacts of other parts throughout the life cycle, which may lead to fragmented or even conflicting decisions. A rational design of environmental regulation policy can promote the extension of producer responsibility (Chen and Sheu 2009). Wang et al. (2018) built an evaluation framework to analyse the effects of China's fund policy and stressed the need to design a flexible operation mode associated with environmental protection requirements. In this study, we attempt to provide a redesigned scheme of the fund policy that answers the call for a more holistic view. It is hoped that our findings will contribute to assisting policymakers in their task of promoting e-waste management and achieving systematic sustainability.

\section{The fund policy redesign based on the closed-loop life cycle}

This section provides a conceptual framework of redesigned fund policy to demonstrate its operational mechanism clearly and then present the basic data and related models. Due to the lag in statistical data, only historical time-series data of EEE until 2018 can be collected at the time of submission. We use real data between 2007 and 2018 to make future predictions.

\section{Framework description}

In general, the lifecycle phase of EEE flow starts from production by primary producers, flows into social consumption, and then becomes e-waste when it reaches 
its end-of-life after a certain period (Cucchiella et al. 2015). E-waste is either collected and dismantled by formal/informal recyclers or simply dropped into other solid wastes. In the past, policymakers focused only on the disposal phase rather than the closed-loop life cycle, which led to several serious challenges mentioned before. Since the resource system and the fund system mutually interact, the fund policy should not be introduced in an isolated manner but need to combine incentives for upstream production and downstream recycling from a closed-loop lifecycle perspective. This section attempts to redesign the fund policy from the closed-loop lifecycle perspective, building on the current fund policy with two basic EPR instruments, consumer-oriented deposits, and recycling content standards to achieve long-term dynamic sustainability goals (Kaffine and O'Reilly 2013). Consumer-oriented deposits, also regarded as refunds, are charged at the sales points for EEE and are returned after e-waste is turned into proper collection points (Tojo et al. 2001). Recycling content standards are mandates using specific percentages of secondary resources from e-waste to produce new products (Tojo et al. 2001).
In terms of how this redesign addresses challenges and facilitates the e-waste management system, we can see that (1) connecting the upstream to the downstream of the entire life cycle must rest on the direct effects of resource flows, and recycling content standards alter parts of the virgin resources in favour of closing the resource loop and increasing the amount of e-waste recycled. (2) Consumer deposits increase the fund input channels while placing transactions between consumers and formal recyclers, fundamentally energising the e-waste market. Turning to system goals, it is vital to close the resource use loop by encouraging the use of secondary resources and ensuring a sustainable supply of resources. Apart from this, it is paramount to ensure that adequate funds are available to support related activities, such as incentives for green design, and to adjust the magnitude flexibly rather than fixing them. Figure 1 represents a conceptual framework of this operation approach, which helps to visually illustrate the simple conceptual relationships and how goals and EPR tools can be fit into the product life cycle.
Fig.1 A conceptual framework of redesigned fund policy

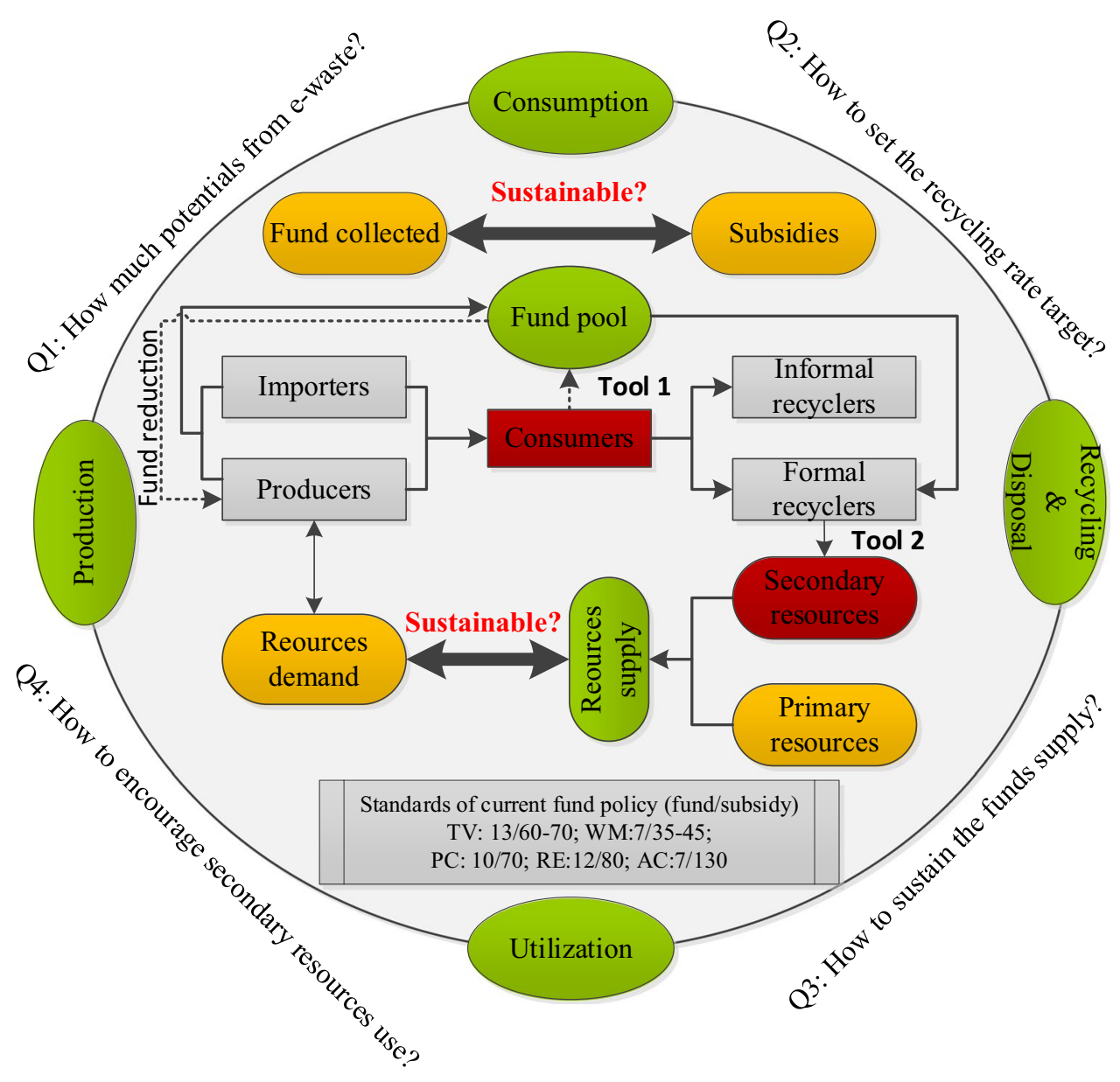




\section{Models}

We propose a reasonable methodology to achieve sustainable development by understanding potential future trends in resources and revenues. The advantage of our models is that they fully consider the changes in product flows over the next decade, ensure that funds can support activities such as subsidies, funding reductions, and deposit returns, and realise the task of optimising the e-waste management system. The operation pathway is divided into four main steps, each of which requires appropriate mathematical models, as follows:

(1) Quantitative evaluation of each selected e-waste generation ("EEE obsolete quantity estimation model").

(2) Sustainable resource availability analysis for valuable materials ("Resource supply model").

(3) Sustainable financial availability analysis to support related activities ("Fund supply model").

(4) Sensitivity analysis of key variables to test the feasibility of redesigned models ("Results analysis").

\section{EEE obsolete quantity estimation model}

Data description We collected all available data needed for this study. Time-series data on domestic production and imports/exports of EEE were collected for the period 2007-2018 from the China Statistical Yearbook (China NBS 2007-2018). Data on the composition and market prices of specific resources contained in e-waste were obtained from related literature and websites (Akcil et al. 2015, Li et al. 2008, Parajuly and Wenzel 2017, U.S. Geological Survey 2010-2019, Zeng et al. 2016). Accordingly, the fund policy model is redesigned, specifically including an EEE sales model, an obsolete quantity estimation model, a resource supply model, and a fund supply model. For a clearer introduction, the parameters involved in the models are explained in detail, as shown in Table 1.
EEE sales model It is essential to know the quantity of EEE consumption $Q_{i j}$, which is attributed to domestic production $P_{i j}$, exports $E_{i j}$, and imports $I_{i j}$. Therefore, the total consumption amount of EEE of category $i$ in year $j$ can be defined by Eq. 1 .

$Q_{i j}=P_{i j}+I_{i j}-E_{i j}$

Obsolete quantity estimation model As mentioned before, EEE becomes fatigued after being used repeatedly during their lifetime and then flows out as e-waste. This phenomenon can be described by the Weibull distribution, which has been adopted for e-waste estimation in many precious studies and is considered the most available method (Balde et al. 2015). Accordingly, the Weibull statistical distribution is used in this study to model the estimation of e-waste (Mueller et al. 2007). In particular, the probability density function (Weibull and Rockey 1962) is given by Eq. 2.

$f(t ; \beta, \vartheta)=\left\{\begin{array}{cc}\frac{\beta}{\vartheta}\left(\frac{t}{\vartheta}\right)^{\beta-1} e^{-(x / \vartheta)^{\beta}} & t \geq 0 \\ 0 & t<0\end{array}\right.$

where $\beta$ is the shape parameter $(\beta>0)$, which determines the shape of the Weibull density function, and $\vartheta$ is the scale parameter $(\vartheta>0)$, which represents the corresponding position of the peak of the function graph on the horizontal axis.

Based on the Weibull density function $f(t ; \beta, \vartheta)$ and the EEE consumption $Q_{i j}$, we set $t=j-2007$, then the e-waste $G_{i j}$ generated in year $j$ can be determined by Eq. 3 .

$G_{i j}=f_{i}(t) Q_{i, j-t}=f_{i}(j-2007) \times Q_{i, 2007}+f_{i}(j-2008) \times Q_{i, 2008}+\cdots+f_{i}(1) \times Q_{i, j-1}$

\section{Resource supply model}

Resources contained in e-waste can obviously provide a choice to supply resources of the EEE industry, as many studies proposed. According to the model from the literature (Sugiyama and Koonsed 2017), in order to ensure a sustainable resource supply for the EEE industry in the future 10 years, based on the recycling content standard, we define

Table 1 Explanation of parameters

\begin{tabular}{llll}
\hline$Q_{i j}$ & Consumption quantity of EEE & $\rho_{i j}$ & Green product ratio \\
$P_{i j}$ & Domestic production quantity of EEE & $r_{i}$ & Recycling rate \\
$E_{i j}$ & Exports quantity of EEE & $l_{k i}$ & Extraction loss rate \\
$I_{i j}$ & Imports quantity of EEE & $\theta_{k i}$ & The $k_{t h}$ resource amount embedded in a product \\
$G_{i j}$ & Generation quantity of e-waste & $F_{i j}$ & Sustainability of fund supply \\
$f(\mathrm{t} ; \beta, \vartheta)$ & Weibull density function & $f_{i}$ & Fund standard \\
$\gamma_{i}$ & Refund participation rate & $c_{i}$ & Consumer deposit \\
$R_{i j}$ & Sustainability of secondary resource supply & $s_{i}$ & Subsidy standard \\
$\tau_{k i}$ & Recycling content standard & $i, j, k$ & $i$, product category; $j$, year; $k$, resource type \\
\hline
\end{tabular}


the sustainability of the secondary resource supply as $R_{i j}$ to establish a sustainable resource supply model (from 2021 to 2030), as in Eq. 4.

$R_{i j}=\left(\left(1-l_{k i}\right) r_{i} G_{i j}-\rho_{i j} Q_{i j} \tau_{k i}\right) \theta_{k i}$

In this model, we focus on the measurement of two indicators. First, we estimate the demand for secondary resources in the EEE industry and set the recycling content standard which is $\tau_{k i}$. Since the EEE industry can use natural resources in addition to secondary resources, green and nongreen products coexist in the EEE market. Unlike nongreen products that use all primary resources, green products contain secondary resources that meet the recycling content standard and reach the quality of primary resources. We assume that the proportion of green products is $\rho_{i j}$ and the amount of $k_{t h}$ resource embedded in a product is $\theta_{k i}$. Second, we measure the secondary resource supply capacity of e-waste. Technology and equipment are significantly important for extracting secondary resources, but this is still a vital obstacle in developing countries, especially China. This means that the loss rate of precious resources should be considered, and we assume it is $l_{k i}$ in our case.

The resource supply model, together with the recycling content standard $\tau_{k i}$ and other parameters, can provide the government with management information, such as the recycling rate $r_{i}$. If it is likely to keep a balance of secondary resources, namely, $R_{i j} \geq 0$, then we can obtain that the recycling rate $r_{i}$ should satisfy a certain condition: $r_{i} \in\left[\max _{j}\left(\frac{\rho_{i j} Q_{i j} \tau_{k i}}{\left(1-l_{k i}\right) G_{i j}}\right), 1\right]$.

\section{Fund supply model}

Arguably, a common theme in some articles presents a view that China's e-waste fund policy-along with support schemes-has encountered financial obstacles that, as mentioned before, have resulted in less-than-expected environmental and economic performance. In a study by Yu et al. (2010), where China's e-waste pilot projects are studied, the authors stressed the need to redesign management policies and proposed that deposits be returned to consumers as an incentive to surrender e-waste. Subsequently, Gu et al. (2017) redesigned the e-waste fund mode by adding consumer pay parts as a financing way to achieve a sustainable fund system, which inspires our case. But the difference is that in this study, we advocate and attempt to provide more systematic and flexible thinking by adding a consumer-oriented deposit measure rather than simple consumer payment to achieve better financial sustainability $F_{i j}$ with higher take-back rate requirements. The fund supply model can be represented by Eq. 5 .

$F_{i j}=\left(f_{i}+c_{i}-\rho_{i j} f_{i}\right) Q_{i j}-\left(s_{i}+\gamma_{i} c_{i}\right) r_{i} G_{i j}$
The deposits $c_{i}$ is commonly used to encourage refund participation (Mallawarachchi and Karunasena 2012). We set the refund participation rate to $\gamma_{i}$. Note that in order to reroute e-waste from the informal to the formal sector, the numerical value of the deposit should be set high enough to encourage participation but not so high as to affect consumers' ability to purchase EEE adversely. According to Eq. 5, the satisfaction condition of the consumer deposit can be obtained: $c_{i} \geq \max _{j}\left(\frac{s_{i} r_{i} G_{i j}-\left(1-\rho_{i j}\right) f_{i} Q_{i j}}{Q_{i j}-\gamma_{i} r_{i} G_{i j}}\right)$.

\section{Results analysis}

This section first examines the future trend in e-waste and total funds in-out. Since the current fund policy was implemented in 2012, we show the results for the period 2012-2030. Next, we perform a basic scenario analysis of the redesigned fund policy using TV waste as a case study and then conduct sensitivity analysis with four additional scenarios.

\section{E-waste tendency under the current fund policy}

The quantities of EEE consumed and e-waste generated in China from 2012 to 2030 are shown in Fig. 2. There is a large gap between the total consumption curve and the total scraped curve, while both grow steadily at an average rate of $10.29 \%$ and $11.04 \%$, reaching 876.75 million and 1583.54 million units, respectively, in 2030 . These tendencies provide the possibility of realising a sustainable resource supply of the EEE production based on recycled resources from e-waste. In terms of individual streams, the quantities of PC consumption and scraped grow fastest, followed by AC, $\mathrm{TV}, \mathrm{WM}$, and RF. The scraped quantity of TV, for instance, rapidly grows from 7.89 million units to 108.83 million units from 2012 to 2030, while the quantity of TV consumed in 2030 is almost four times the 59.85 million units consumed in 2012. Based on the current fund standards, three lines of

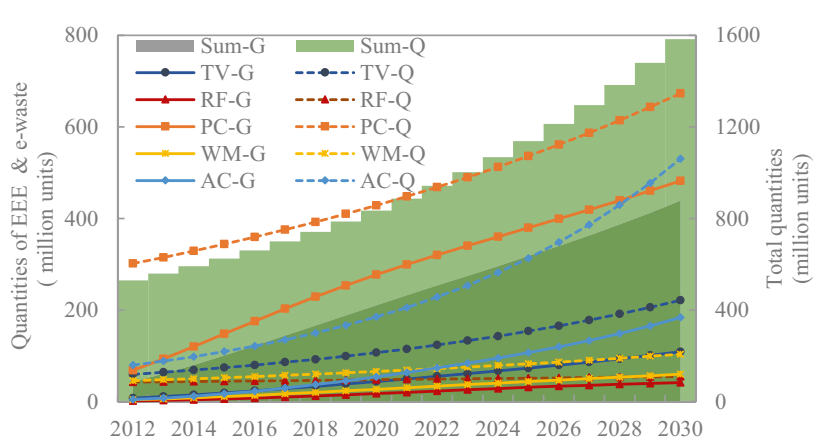

Fig. 2 Individual and total quantities of EEE and e-waste 


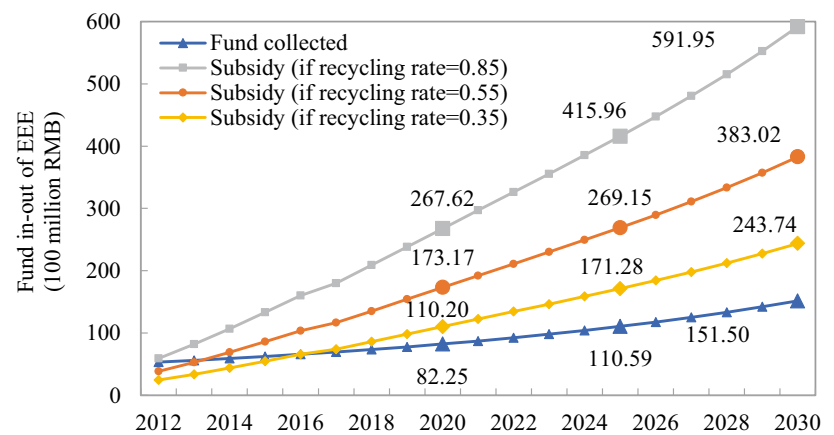

Fig. 3 Total fund in-out of EEE under fund policy

subsidies are assumed: the upper line $\left(r_{i}=0.85\right)$, the baseline $\left(r_{i}=0.55\right)$, and the lower line $\left(r_{i}=0.35\right)$. As seen in Fig. 3, even with a recycling rate of 0.55 , the fund pool will be in deficit by 2023 . The higher the recycling rate, the more subsidies and thus the faster the deficit. It indicates that the current fund policy is encountering a financial crisis because of the staggering growth of e-waste, so the redesign of the e-waste management policy should be taken seriously (Zeng et al. 2016).

\section{Effects of the redesigned fund policy}

TV waste has always been favoured in the e-waste industry due to its high benefits. In 2019, about 0.84 billion e-waste was processed by 94 certified recyclers in China's 29 provinces, $51.74 \%$ of which were TV (Ministry of Ecology and Environment of People's Republic of China 2020). According to our prediction, the total amount of funds collected from TV producers cannot cover the subsidies for TV waste at a recycling rate of 0.55 or greater under the current fund policy after 2022, as shown in Fig. 4. Thus, in this section, TV waste is employed as a case study to further analyse the feasibility of the redesigned policy in terms of fund supply and the resource supply. Materials embedded in products can be recycled and repurposed to achieve economic convenience. In fact, the products are usually not homogeneous due to the mix of materials. The profitability of recycling is driven by the inclusion of key and valuable resources,

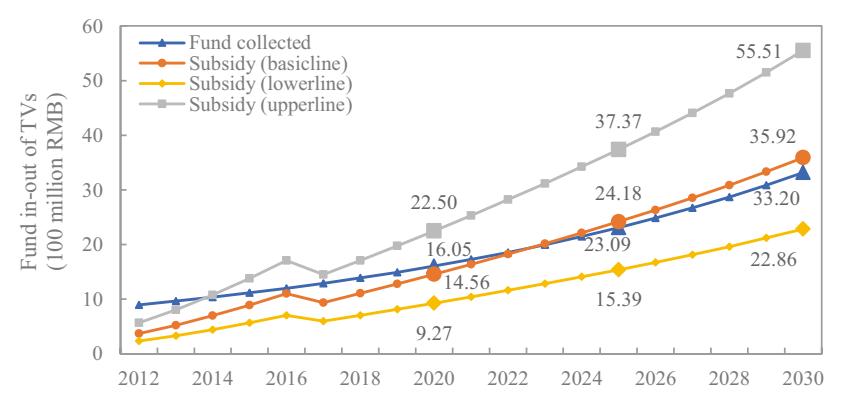

Fig. 4 Fund in-out of TV under fund policy which is a primary consideration for the e-waste industry. Therefore, it is appropriate to make an economic assessment by multiplying the market price by the potential recycling quantity. The purpose is to select the resource category with the highest economic potential for recycling. We can obtain that the most valuable resource in TV is copper, so in this case, the goal is to meet the supply of copper.

The basic parameter values adopted from the existing literature (Chi et al. 2014; Fogarasi et al. 2014; Palmer and Walls 1997; Zeng et al. 2016) are set as follows: $\theta_{k i}=824 \mathrm{~g} /$ unit $, l_{k i}=0.07, \tau_{k i}=0.35, \gamma_{i}=0.70$. In addition, it is thought that with the legal enforcement and ethical standards increase, more producers will practice the use of secondary resources. Hence, it is assumed that the annual growth rate of green products is $3 \%$, with an initial value of 0.40 (Santolaria et al. 2011). According to these basic parameters, we can obtain the standard of the recycling rate $r_{i} \in[0.42,1]$ and set $r_{i}=0.55$. Correspondingly, the range of the consumer deposit, $c_{i} \geq 11.50$, can be obtained, and we set the value of hypothetical group $\left(r_{i}, c_{i}\right)$ to $(0.55,12)$ as the basic scenario (scenario $B$ ) to illustrate the sustainable capability in our case, as shown in Fig. 5.

The sustainable supply capability of copper in TV is presented in Fig. 5. Due to the consumption growth, the demand for copper in TV shows an upward trend with an increasing rate of $17.79 \%$ per year. Meanwhile, the supply of secondary copper from TV waste is increasing, and the surplus is gradually expanding at the assumed recycling rate. This means that the redesigned policy realises a sustainable supply of copper for the TV industry through applying the EPR tool of the recycling content standard. Figure 5 discusses an additional "what if" situation where all TVs, rather than some, contain secondary copper. The result shows that at a 35\% recycling content standard, recycled copper cannot satisfy the production needs of all TVs. This emphasises that the recycling rate should cope well with the demand to sustain the resource supply.

In terms of fund supply, with the inclusion of the consumer deposit, we can sustain the fund pool since the funds are higher than subsidies from 2021 to 2030, as shown in Fig. 5. It is noted that in addition to subsidising recyclers,

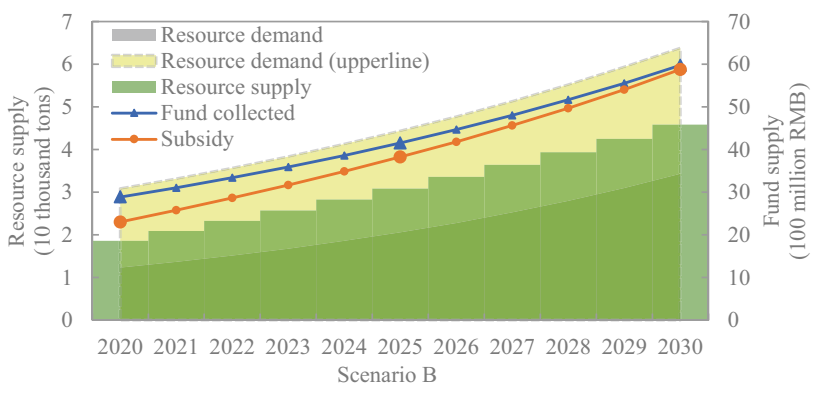

Fig. 5 The sustainable capabilities of TV under redesigned policy 

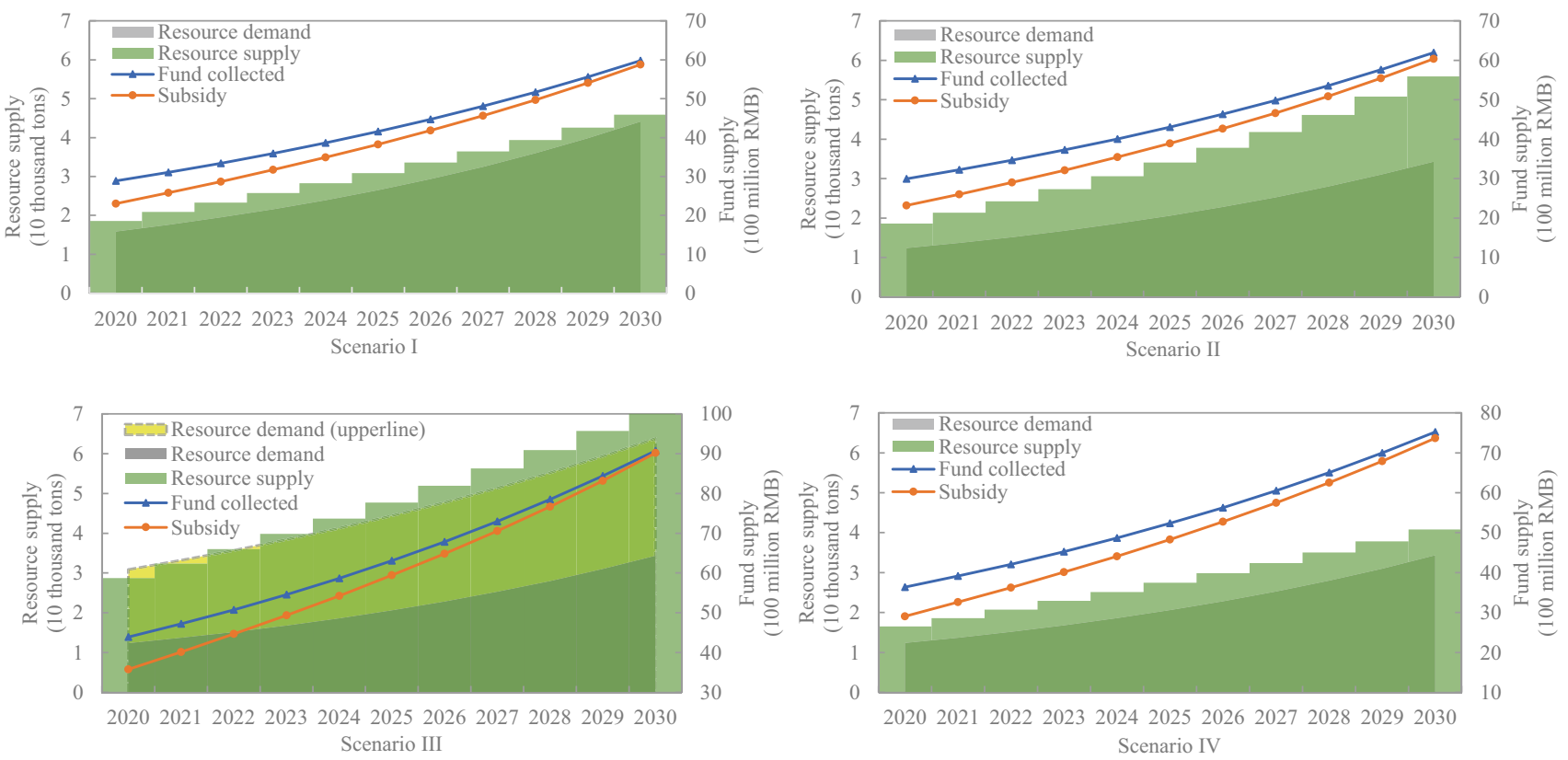

Fig. 6 The sustainable capabilities of TV for different scenarios under redesigned policy

we consider two additional expenditures: (1) rewarding the producers who produce green products with rebate funds and (2) returning deposits to consumers who give back their TV waste. In this way, not only would e-waste be enclosed for resource utilisation, but consumers would also be encouraged to return e-waste to formal collection points due to higher pay, enhancing the competitiveness of formal recyclers. Overall, the redesigned policy could address the challenges of competition posed by informal recyclers and fund deficits, as well as financially support the closure of resource use.

\section{Sensitivity analysis}

In this section, the three key parameters proposed above are chosen as "what if" scenarios to analyse the sensitivity of the redesigned policy compared to scenario B as shown in Fig. 6, which is beneficial for further understanding.

- Scenario I: The recycling content standard is increased to $45 \%$.

- Scenario II: The recycling rate increases from 0.55 at an annual rate of $3 \%$.

- Scenario III: The recycling rate is required to reach $85 \%$, which is the international standard set by the EU (Directive 2012/19/EU).

- Scenario IV: The loss rate of precious resources increases to $30 \%$.
Even though the closed-loop scheme has obtained support from China's government, the specific plan is still unclear at the moment. In scenario I, we aim to observe whether the redesigned policy can cope with changes in the recycling content standard. When a higher resource content is required, which obviously leads to greater demand, then a new standard of the recycling rate $r_{i} \in[0.53,1]$ can be obtained. Scenario B still meets this condition. However, it is clear that if a higher recycling content is required, scenario $\mathrm{B}$ needs to be further adjusted to maintain the sustainable capacities both of resources and funds.

However, if we directly change the recycling rate with a growth rate of $3 \%$, due to the increase in subsidies, the consumer deposit standard would change from 12 to 13 to maintain the sustainability of the fund system. Scenario I and scenario II illustrate that the recycling rate is positively related to the recycling content standard. Both, in turn, affect the sustainability of the fund system and sometimes require further adjustments to the consumption deposit. Scenario III further confirms that there is a significant increase in the consumer deposit, i.e. $c_{i} \geq 25.65$, when the recycling rate increases. Actually, in this case, the supply capability of secondary copper can satisfy the maximum production demand of all TVs rather than only a fraction of them. Thus, we verify the claim that e-waste is urban minerals, and at the same time, we believe that increasing the formal recycling rate is of great significance for achieving resource sustainability.

In scenario IV, reducing the extraction ratio of precious resources has a similar but more significant impact than in 
scenario I. The difference is that due to the loss of resources, the supply is reduced, while the demand remains constant, requiring a higher recycling rate, i.e. $r_{i} \in[0.59,1]$. Accordingly, the consumer deposit is enhanced, i.e. $c_{i} \geq 18.07$, and we set $\left(r_{i}, c_{i}\right)=(0.70,19)$ in scenario III to input more resources and funds in order to keep sustainability. Scenario IV does not significantly increase the supply of copper compared to scenario B. Because a large amount of copper is wasted by backward and inefficient treatment means, which often occurs with informal recyclers, this stresses the need to treat e-waste properly in addition to the importance of technological innovation so that e-waste can play an optimal role as an urban mineral for sustainable development.

\section{Discussion}

With our redesigned model, we consider the sustainable resource supply and fund supply of the e-waste fund policy and examine the efficiency of a proper adjustment scheme through four scenarios. It can be found that the current fund policy is not necessarily effective in e-waste management. We argue that the first required adjustment to the fund policy is to include consumer deposits to the fund pool to support higher recycling rates and other economic incentive activities. This scheme would effectively reduce the financial pressure on the government and increase consumers' motivation to return their e-waste. Only then would the government fully shift financial responsibility to the "producers". The same government department would best develop the consumer deposit system as the current fund policy, which should also be responsible for the e-waste market system, including cyberinfrastructure maintenance, data management, etc.

Given that recycling content standards are shaped by vigorously promoting circularity, it appears necessary to recognise that policies should mandate a certain percentage of recycled resources for particular consumption goods. For example, the USA enforced newsprint to contain recycled papers. Japan has implemented laws on green purchasing that require the public sector to buy products partly made of recycled resources, such as EEE, office automation machines, and vehicles. Even though China has not yet issued specific implementation schemes, the redesigned fund policy is clearly aimed at improving recycling rates under the recycling content standard, based on "closing the loop" of the product life cycle. However, it may not be good for producers and consumers, as the use of recycled resources can reduce the quality of products relative to virgin material. Thus, producers need to invest more in technological innovations, and consumers should be involved in green consumption.

In doing so, another issue that should be mentioned is consumers' knowledge and awareness of e-waste. Lack of awareness, insufficient information, moral norms, environmental beliefs, and sociodemographic factors (e.g. age, gender) have been examined significantly affect consumers' motivation to return e-waste. Thus, the government has a vital role in the efficiency of the redesigned fund policy and has to know how to provide related programs to improve consumers' attitudes towards e-waste recycling. In fact, consumers demand more information on where they can recycle their e-waste instead of why they should recycle (Islam et al. 2021). Thus, the construction and improvement of proper recycling facilities are the first step in offering available recycling services. Meanwhile, with the skyrocketing online market development, it is necessary to consider e-commerce as an essential element of the e-waste management system. In light of this, the use of the Internet of Things (IoT) and big data analytics could provide new insights into the formal e-waste trade.

In addition, the results of comparative sensitivity analysis can all be adjusted to the characteristics of the different parameters. Obviously, the target recycling rate is positively correlated with the recycling content standard. From the perspective of resource extraction, reducing the loss rate also seems to be a favourable scheme since it avoids resource wastage, which often occurs in informal recycling systems. Therefore, the government can continuously encourage high-tech innovations in resource extraction while carrying out formalisation programs for informal recycling. It is important to note that the standards of the redesigned policy, such as recycling content standards, recycling rates, and consumer deposits, need to be adjusted according to product differences because of the individual treatment of various e-waste types. In the long run, a better scheme would also consider the encouragement of green production, which has been examined in the existing literature (Liu et al. 2020; Zhao and Bai 2021), and appropriate incentives can improve producers' willingness of green production, and it seems to be another important avenue of e-waste management.

\section{Conclusions}

The e-waste management policy has a substantial impact on the regularisation of the e-waste industry and the utilisation of secondary resources. This study applies EPR theory to redesign the current e-waste fund policy by integrating two typical EPR instruments: recycling content standards and consumer-oriented deposits. In addition to addressing the deficit challenge of the fund system, this approach encourages the use of secondary resources, which is consistent with the original intent of the fund policy. It also highlights the crucial role of consumer behaviour in making formal recyclers more competitive by giving back the e-waste in the form of deposits. Additionally, this study examines the 
roles of three vital factors-recycling contents standards, recycling rate, and resource extraction rate-in achieving dynamic management.

This study has some limitations. For example, there lack surveys on Chinese consumers' willingness to deposit, such as the one conducted by Islam et al. (2021), which may be of interest. Although the new model is generic, the situation is different for different e-waste. Due to the limited scale of this study, only TV waste is chosen as a case for policy-made analysis. In addition, future studies could extend the scope to e-waste that is not in the management catalogue, such as small household appliances that have not yet attracted the attention of policymakers.

\section{Data and materials availability}

The datasets used and/or analysed during the current study are available from the corresponding author and first author on reasonable request.

Author contribution Conceptualization, TT and GL; methodology, TT; data curation, HY and TT; software, HY; formal analysis, TT and HY; validation, YL; writing — original draft, TT; writing — review and editing, YL; funding acquisition, GL; supervision, YL and GL.

Funding Open access funding provided by Linköping University. The work has been supported by the National Social Science Foundation of China (No.15ZDC030) and the International Exchange Program for Graduate Students of Tongji University (no. 201902058).

\section{Declarations}

Ethical approval Not applicable.

Consent to participate Not applicable.

Consent for publication All the authors have approved the manuscript for publication.

Conflict of interest The authors declare no competing interests.

Open Access This article is licensed under a Creative Commons Attribution 4.0 International License, which permits use, sharing, adaptation, distribution and reproduction in any medium or format, as long as you give appropriate credit to the original author(s) and the source, provide a link to the Creative Commons licence, and indicate if changes were made. The images or other third party material in this article are included in the article's Creative Commons licence, unless indicated otherwise in a credit line to the material. If material is not included in the article's Creative Commons licence and your intended use is not permitted by statutory regulation or exceeds the permitted use, you will need to obtain permission directly from the copyright holder. To view a copy of this licence, visit http://creat ivecommons.org/licenses/by/4.0/.

\section{References}

Akcil A, Erust C, Gahan CS, Ozgun M, Sahin M, Tuncuk A (2015) Precious metal recovery from waste printed circuit boards using cyanide and non-cyanide lixiviants-a review. Waste Manage 45:258-271

Arya S, Kumar S (2020) E-waste in India at a glance: current trends, regulations, challenges and management strategies. Journal of Cleaner Production: 122707

Balde CP, Kuehr R, Blumenthal K, Fondeur Gill S, Kern M, Micheli P, Magpantay E, Huisman J (2015) E-waste statistics-guidelins on classification, reporting and indicators", United Nations University, IAS-SCYCLE, Bonn (Germany) 2015, 51 pages (ISBN Print: 978-92-808-4553-2)(with CP Balde, K. Blumenthal, S. Fondeur Gill, M. Kern, P. Micheli, E. UNU)

Berežni I, Castro FD, Batinić B, Vaccari M, Stanisavljevic N (2021) WEEE treatment and system management in Italy and Serbia: a comparison. Waste Manage Res 39:1302-1316

Botello-Álvarez JE, Rivas-García P, Fausto-Castro L, Estrada-Baltazar A, Gomez-Gonzalez R (2018) Informal collection, recycling and export of valuable waste as transcendent factor in the municipal solid waste management: a Latin-American reality. J Clean Prod 182:485-495

Cai K, Song Q, Peng S, Yuan W, Liang Y, Li J (2020) Uncovering residents' behaviors, attitudes, and WTP for recycling e-waste: a case study of Zhuhai city, China. Environ Sci Pollut Res 27:2386-2399

Cao J, Lu B, Chen Y, Zhang X, Zhai G, Zhou G, Jiang B, Schnoor JL (2016) Extended producer responsibility system in China improves e-waste recycling: government policies, enterprise, and public awareness. Renew Sustain Energy Rev 62:882-894

Chen YJ, Sheu J-B (2009) Environmental-regulation pricing strategies for green supply chain management. Transportation Research Part e: Logistics and Transportation Review 45:667-677

Chi X, Streicher-Porte M, Wang MY, Reuter MA (2011) Informal electronic waste recycling: a sector review with special focus on China. Waste Manage 31:731-742

Chi X, Wang MY, Reuter MA (2014) E-waste collection channels and household recycling behaviors in Taizhou of China. J Clean Prod 80:87-95

China NBS (2007-2018) China Statistical Yearbook. http://www.stats. gov.cn/tjsj/ndsj/. Accessed 20 June 2021

Cucchiella F, D’Adamo I, Koh SL, Rosa P (2015) Recycling of WEEEs: an economic assessment of present and future e-waste streams. Renew Sustain Energy Rev 51:263-272

de Albuquerque CA, Mello CHP, Gomes JHdF, Santos VCd, Zara JV (2020) E-waste in the world today: an overview of problems and a proposal for improvement in Brazil. Environ Qual Manage 29:63-72

Ezeah C, Fazakerley JA, Roberts CL (2013) Emerging trends in informal sector recycling in developing and transition countries. Waste Manage 33:2509-2519

Fogarasi S, Imre-Lucaci F, Imre-Lucaci Á, Ilea P (2014) Copper recovery and gold enrichment from waste printed circuit boards by mediated electrochemical oxidation. J Hazard Mater 273:215-221

Fu J, Zhong J, Chen D, Liu Q (2020) Urban environmental governance, government intervention, and optimal strategies: a perspective on electronic waste management in China. Resour Conserv Recycl 154:104547

State Taxation Administration of People's Republic of China (2012) The administrative measure on tax levy and use for WEEE recycling. http://www.chinatax.gov.cn/n810341/n810765/n812151/ n812401/c1082760/content.html. Accessed 20 June 2021

Gu Y, Wu Y, Xu M, Mu X, Zuo T (2016) Waste electrical and electronic equipment (WEEE) recycling for a sustainable resource supply in the electronics industry in China. J Clean Prod 127:331-338 
Gu Y, Wu Y, Xu M, Wang H, Zuo T (2017) To realise better extended producer responsibility: redesign of WEEE fund mode in China. J Clean Prod 164:347-356

Guo Q, Wang E, Nie Y, Shen J (2018) Profit or environment? A system dynamic model analysis of waste electrical and electronic equipment management system in China. J Clean Prod 194:34-42

Hischier R, Wäger P, Gauglhofer J (2005) Does WEEE recycling make sense from an environmental perspective?: The environmental impacts of the Swiss take-back and recycling systems for waste electrical and electronic equipment (WEEE). Environ Impact Assess Rev 25:525-539

Hong I-H, Lee Y-T, Chang P-Y (2014) Socially optimal and fund-balanced advanced recycling fees and subsidies in a competitive forward and reverse supply chain. Resour Conserv Recycl 82:75-85

Ilankoon I, Ghorbani Y, Chong MN, Herath G, Moyo T, Petersen J (2018) E-waste in the international context-a review of trade flows, regulations, hazards, waste management strategies and technologies for value recovery. Waste Manage 82:258-275

Islam MT, Huda N, Baumber A, Shumon R, Zaman A, Ali F, Hossain R, Sahajwalla V (2021) A global review of consumer behavior towards e-waste and implications for the circular economy. J Clean Prod 128297

Kaffine D, O'Reilly P (2013) What have we learned about extended producer responsibility in the past decade? A survey of the recent EPR economic literature. Organisation for Economic Co-operation and Development (OECD)

Li J, Wu Z, Zhang H-C (2008) Application of neural network on environmental impact assessment tools. Int J Sustain Manuf $1: 100-121$

Li J, Zeng X, Chen M, Ogunseitan OA, Stevels A (2015) "ControlAlt-Delete": rebooting solutions for the e-waste problem. Environ Sci Technol 49:7095-7108

Li W, Achal V (2020) Environmental and health impacts due to e-waste disposal in China-a review. Sci Total Environ 737:139745

Liu G, Xu Y, Tian T, Wang T, Liu Y (2020) The impacts of China's fund policy on waste electrical and electronic equipment utilisation. J Clean Prod 251:119582

Liu X, Lin K, Wang L (2021) Stochastic evolutionary game analysis of e-waste recycling in environmental regulation from the perspective of dual governance system. J Clean Prod 319:128685

Liu Z, Tang J, Li B-y, Wang Z (2017) Trade-off between remanufacturing and recycling of WEEE and the environmental implication under the Chinese fund policy. J Clean Prod 167:97-109

Mallawarachchi H, Karunasena G (2012) Electronic and electrical waste management in Sri Lanka: suggestions for national policy enhancements. Resour Conserv Recycl 68:44-53

Mayyas A, Qattawi A, Omar M, Shan D (2012) Design for sustainability in automotive industry: a comprehensive review. Renew Sustain Energy Rev 16:1845-1862

Ministry of Ecology and Environment of People's Republic of China (2020) Nation annual report on prevention and control of solid waste pollution in large-and medium-sized cities. https://www. mee.gov.cn/hjzl/sthjzk/gtfwwrfz/. Accessed 20 June 2021

Mueller DB, Cao J, Kongar E, Altonji M, Weiner P-H, Graedel aT (2007) Service lifetimes of mineral end uses. US Geological Survey (USGS)

Nixon H, Saphores J-DM (2007) Financing electronic waste recycling Californian households' willingness to pay advanced recycling fees. J Environ Manage 84:547-559

Ogunniyi I, Vermaak MKG, Groot D (2009) Chemical composition and liberation characterisation of printed circuit board comminution fines for beneficiation investigations. Waste Manage 29:2140-2146

Palmer K, Walls M (1997) Optimal policies for solid waste disposal taxes, subsidies, and standards. J Public Econ 65:193-205
Parajuly K, Wenzel H (2017) Potential for circular economy in household WEEE management. J Clean Prod 151:272-285

Patil RA, Ramakrishna S (2020) A comprehensive analysis of e-waste legislation worldwide. Environ Sci Pollut Res 27:14412-14431

Puig-Ventosa I (2004) Potential use of feebate systems to foster environmentally sound urban waste management. Waste Manage $24: 3-7$

Santolaria M, Oliver-Solà J, Gasol CM, Morales-Pinzón T, Rieradevall J (2011) Eco-design in innovation driven companies: perception, predictions and the main drivers of integration. The Spanish example. J Clean Prod 19:1315-1323

Shittu OS, Williams ID, Shaw PJ (2021) Global e-waste management: can WEEE make a difference? A review of e-waste trends, legislation, contemporary issues and future challenges. Waste Manage 120:549-563

Sovacool BK (2019) Toxic transitions in the lifecycle externalities of a digital society: the complex afterlives of electronic waste in Ghana. Resour Policy 64:101459

Statista (2021) Leading countries based on generation of electronic waste worldwide in 2019. https://www.statista.com/statistics/ 499952/ewaste-generation-worldwide-by-major-country/. Accessed 20 June 2021

Streicher-Porte M (2006) SWICO/S. EN. S, The Swiss WEEE recycling systems and best practices from other European systems, Proceedings of the 2006 IEEE International Symposium on Electronics and the Environment, 2006. IEEE, pp. 281-287

Sugiyama Y, Koonsed P (2017) Environmental R\&D, imperfectly competitive recycling market, and recycled content standards. Econ Bull 37:2970-2979

Tang A, Wang L (2014) Discussion on the development and trend of dismantling industry of waste electric and electronic products. Recycl Resour Circ Econ 17:21-24

Tojo N, Lindhqvist T, Davis G (2001) EPR programme implementation: institutional and structural factors, Proceeding of OECD Seminar on Extended Producer Responsibility, Paris, France. Citeseer, pp. 13-14

U.S. Geological Survey (2010-2019) National Minerals Information Center. https://www.usgs.gov/centers/nmic/commodity-stati stics-and-information. Accessed 20 June 2021

Uwasu M, Naito T, Yabar H, Hara K (2013) Assessment of Japanese recycling policies for home electric appliance: cost-effectiveness analysis and socioeconomic and technological implications. Environ Dev 6:21-33

Wang B, Ren C, Dong X, Zhang B, Wang Z (2019) Determinants shaping willingness towards online recycling behaviour: an empirical study of household e-waste recycling in China. Resour Conserv Recycl 143:218-225

Wang J, Wang Y, Zhang S, Zhang M (2018) Effects of fund policy incorporating extended producer responsibility for WEEE dismantling industry in China. Resour Conserv Recycl 130:44-50

Weibull W, Rockey K (1962) Fatigue testing and analysis of results. J Appl Mech 29:607

Xu J, Ye M, Lu W, Bao Z, Webster C (2021) A four-quadrant conceptual framework for analysing extended producer responsibility in offshore prefabrication construction. J Clean Prod 282:124540

Xue Y, Wen Z, Bressers H, Ai N (2019) Can intelligent collection integrate informal sector for urban resource recycling in China? J Clean Prod 208:307-315

Yang J, Lu B, Xu C (2008) WEEE flow and mitigating measures in China. Waste Manage 28:1589-1597

Yang X, Miao X, Wu J, Duan Z, Yang R, Tang Y (2020) Towards holistic governance of China's e-waste recycling: evolution of networked policies. Int J Environ Res Public Health 17:7407 
Yu J, Williams E, Ju M, Shao C (2010) Managing e-waste in China: policies, pilot projects and alternative approaches. Resour Conserv Recycl 54:991-999

Zeng X, Gong R, Chen W-Q, Li J (2016) Uncovering the recycling potential of "new" WEEE in China. Environ Sci Technol 50:1347-1358

Zeng X, Duan H, Wang F, Li J (2017) Examining environmental management of e-waste: China's experience and lessons. Renew Sustain Energy Rev 72:1076-1082

Zeng X, Ali SH, Tian J, Li J (2020) Mapping anthropogenic mineral generation in China and its implications for a circular economy. Nat Commun 11:1-9
Zhang S, Ding Y, Liu B, Da P, Chang C-c, Volinsky AA (2015) Challenges in legislation, recycling system and technical system of waste electrical and electronic equipment in China. Waste Manage 45:361-373

Zhao X, Bai X (2021) How to motivate the producers' green innovation in WEEE recycling in China?-An analysis based on evolutionary game theory. Waste Manage 122:26-35

Publisher's Note Springer Nature remains neutral with regard to jurisdictional claims in published maps and institutional affiliations. 